\title{
GEOGRAPHIC INFORMATION SYSTEM FOR DROUGHT RISK MAPPING IN AUSTRALIA - DROUGHT RISK ANALYSER WEB APP
}

\author{
C. Sun ${ }^{1}$, S. Choy ${ }^{1, *}$, Z. Chua $^{2}$, I. Aitkenhead ${ }^{2}$, Y. Kuleshov ${ }^{1,2,3, *}$ \\ ${ }^{1}$ School of Science, RMIT University Melbourne, 3000, Australia - (chayn.sun, suelynn.choy, yuriy.kuleshov)@rmit.edu.au \\ ${ }^{2}$ Climate Risk and Early Warning Systems (CREWS), Bureau of Meteorology, Docklands, 3008, Australia - (zhi-weng.chua, \\ isabella.aitkenhead)@bom.gov.au \\ ${ }^{3}$ School of Mathematics and Statistics, The University of Melbourne, Melbourne, 3000, Australia
}

Commission IV

KEY WORDS: Drought Risk Mapping; GIS, Drought Hazard; Drought Vulnerability; Drought Exposure; Drought Preparedness

\begin{abstract}
:
Australia frequently experiences extended periods of severe droughts which have a significant negative impact on populations and economy. To improve preparedness for drought, decision-support tools which provide comprehensive information about current dry conditions are essential. In this paper, we present a conceptual design for a Drought Risk Analyser (DRA) - web-based information App for drought risk mapping developed using geographic information system (GIS). The developed DRA is based on combining Drought Hazard/Vulnerability/Exposure Indices (DHI, DVI and DEI respectively) into a final Drought Risk Index (DRI) for total of 542 Local Government Areas (LGA) in Australia. Drought indicators selected to compute drought hazard - the Standardised Precipitation Index (SPI), the Vegetation Health Index (VHI) and Soil Moisture - were obtained through the World Meteorological Organization (WMO) Space-based Weather and Climate Extremes Monitoring (SWCEM) international initiative. Australian Bureau of Statistics (ABS) census data were used to develop the drought-related population vulnerability index - DVI. Australian national Digital Elevation Model and catchment scale land use data were used to calculate the DEI. Implemented functionality of the designed DRA is illustrated using a case study for the 2019 drought in Australia. The DRA App will be beneficial for Australian farmers and rural communities to assist with decision making, as well as for LGA planners to gain insights on current state of drought risk at both local and national levels. The developed methodology of using space-based observations for assessing drought hazard could be applied for developing similar web-based information tools in drought-prone areas of other countries.
\end{abstract}

\section{INTRODUCTION}

Australia frequently experiences extended periods of severe droughts which have significant negative impact on populations and economy. Coping with regular droughts became a challenging experience for Australia's farmers and rural communities. As a consequence of climate change, droughts will likely be more frequent, longer in duration, and more severe. Droughts will also affect a broader area, which means that farmers and communities who rarely experienced drought are likely to experience it more often. Analysis of drought risk, therefore, is of key importance. To improve preparedness for drought, decision-support tools which provide comprehensive information about current dry conditions are essential. In this paper, we present a conceptual design for a Drought Risk Analyser (DRA) - a web-based information App for drought risk mapping designed using geographic information system (GIS).

\section{DROUGHT IN AUSTRALIA}

Australia is a dry continent and precipitation observations are vital for drought monitoring. To obtain precipitation data, the Australian Bureau of Meteorology (BoM) operates an extensive observation network of more than 6,000 rain gauge stations. Historical precipitation records from archives of the Australian BoM (BoM, 2020) demonstrate that on average, widespread drought in Australia occurs once every 18 years; however, the severity and duration of droughts vary.

\footnotetext{
${ }^{*}$ Corresponding authors
}

As an example, a map of rainfall deciles for Australia in January 2017 - December 2019 derived from the Australian BoM rain gauge observations is presented in Figure 1. The map shows that rainfall over about half of the country was below-average, with rainfall recorded over most parts of the Murray-Darling Basin - the main agricultural region of Australia - being in the lowest decile (or 10 per cent), i.e., indicating that this region was in meteorological drought.

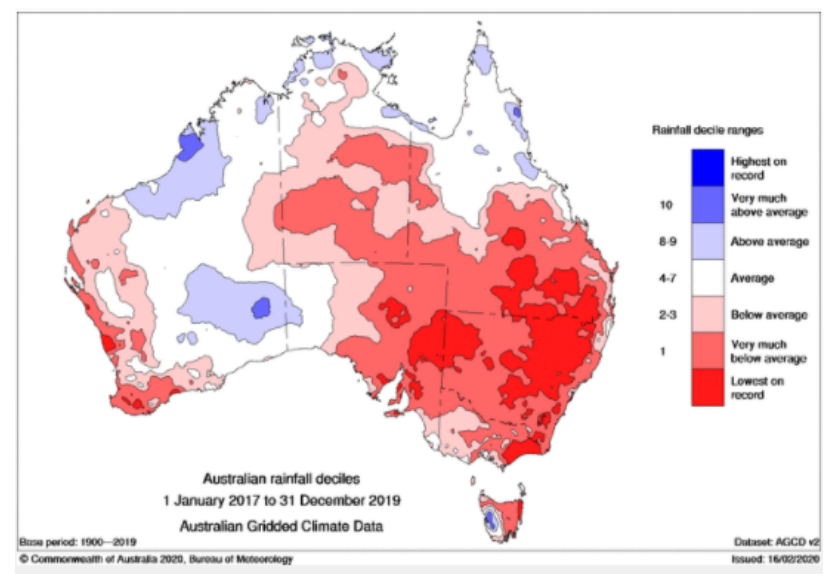

Figure 1. Australian rainfall deciles 2017 - 2019

Surface-based precipitation observations from the Australian BoM rain gauge network provide valuable information for drought monitoring; however, this network has a certain deficiency. Spatial distribution of the surface-based stations is 
not uniform across Australia, as although eastern, southern and south-western areas of the country are densely covered by rain gauge stations, large areas in central Australia have very sparse coverage.

Modern technology - space-based observations - provides global uniform coverage and in this way complements conventional in situ observations. Recognising the importance of enhancing the capacity of meteorological services in providing users with accurate precipitation monitoring products, in 2017 the World Meteorological Organization (WMO) established the Space-based Weather and Climate Extremes Monitoring (SWCEM) international initiative; the first demonstration project was successfully implemented in East Asia and Western Pacific (Kuleshov et al. 2019). WMO SWCEM products were specifically designed to assist with extreme precipitation monitoring, including drought. In our conceptual design of the DRA, WMO SWCEM products were used to assess drought hazard. This is a novel approach which we explored in this study for Australia. The developed methodology of using space-based observations for assessing drought hazard could be applied for developing similar webbased information tools in other regions affected by drought.

\section{DROUGHT RISK ANALYZER}

To achieve the aim, the following objectives are set:

1. Identify and conceptualise the drought risk indicators and key components;

2. Collect spatial datasets for drought risk indicators and build a Drought Risk Index (DRI) database for different levels of indicators;

3. Calculate a DRI in GIS for Australian Local Government Areas (LGAs);

4. Design a web-based GIS application for DRA;

5. Disseminate the DRI indicators and Index in the DRA portal using an interactive dashboard and maps.

\subsection{Drought Risk Indicators}

Assessing drought risk, three elements - drought hazard, drought exposure and drought vulnerability - are usually considered (Carrão et al, 2016; Emrich, Cutter, 2011). For accurate and representative drought risk mapping, it is essential to develop a region-specific DRI which incorporates all three elements (Aitkenhead et al., 2020). In this study, the indicators used for assessing agricultural drought hazard, vulnerability and exposure were selected based on recommendations of a conceptual framework for drought risk assessment (Vogt et al. 2018).

Evaluating the reliability of a user-centred Integrated Early Warning System for Drought, Bhardwaj et al. (2020) demonstrated that using WMO SWCEM products, in combination with the likelihood of exceeding median rainfall in a coming month and the chance of El Niño, for assessment of a region-specific drought hazard at a LGA level allowed to trigger appropriate drought early warnings for five selected LGAs in the Northern Murray-Darling Basin for the significant eastern Australia dry period in 2017-2019. Based on the findings of Aitkenhead et al. (2020) and Bhardwaj et al. (2020), the concept of a region-specific DRI was incorporated into the design of a DRA App.

For drought monitoring, a variety of indicators is used to describe rainfall deficiency, state of vegetation, dryness of soil etc. In earlier studies, the Standardised Precipitation Index (SPI)
(Livada, Assimakopoulos, 2007), the Vegetation Health Index (VHI) (Karnieli et al., 2006) and Soil Moisture (SM) (Atlas, Wolfson, Terry, 1993) were considered as suitable drought indicators to be included in the calculation of the Drought Hazard Index (DHI). Spatial datasets for the SPI, the VHI and SM were obtained from the WMO SWCEM.

Various social and economic factors could be combined into a multidimensional model to assess a population's vulnerability to drought. Following the approach of Aitkenhead et al. (2020) to compute the Drought Vulnerability Index (DVI), the following indicators were selected as representative for Australia: agricultural occupation ( $\%$ of total population in the labour force) and Socio-Economic Indexes for Areas (SEIFA), which is an Australian Bureau of Statistics (ABS) product that ranks areas in Australia according to relative socio-economic advantage and disadvantage. The selected indices are based on information from the five-yearly Census of Population and Housing average household income, and social dependency (\% of population $>15$ and $<64$ years old); data were obtained from the ABS 2016 census (ABS, 2016).

Assessing the exposure to drought, we considered the spatial distribution of two indicators - topography (elevation, slope and north-facing aspect) and land use (crop areas and livestock which characterise agriculture and primary sector activities). For computing drought elevation, the 3 second SRTM Digital Elevation Model Version 1.0 (Geoscience Australia, 2010) dataset was used to derive the average elevation, slope and percentage of north-facing aspect for each LGA. For the computation of the Drought Exposure Index (DEI), land use/cover including drought-sensitive cropland and livestock density were used. The Australian Land Use and Management (ALUM) Classification system provides a nationally consistent method to collect and present land use information for a wide range of users across Australia. The latest version (Version 8) of the classification (ALUM 2016) conforms to the Australian Spatial Data Infrastructure (ASDI) standard for land use datasets.

\subsection{Calculation of the DRI in GIS}

Here we describe three levels of products for drought risk assessment; the conceptual framework for DRI calculation is presented in Appendix 1.

The datasets (the SPI, the VHI, SM, SEIFA data, etc.; level 3 products) selected as indicators for calculating the DHI, DVI and DEI (level 2 products) were standardised and integrated into cumulative indexes using an equal weighted spatial overlay method in the ArcGIS Software (Esri, 2018). Level 3 datasets were transformed into a 0 to 1 scale; values from zero to one were assigned depending on the extent of impact each indicator had on drought hazard, vulnerability and exposure.

The final drought risk index, DRI (level 1 product), was calculated as an average of drought hazard, vulnerability and exposure indices using equation 1:

$$
\mathrm{DRI}=(\mathrm{DHI}+\mathrm{DVI}+\mathrm{DEI}) / 3,
$$

where $\quad$ DHI $=$ Drought Hazard Index, DVI $=$ Drought Vulnerability Index, DEI $=$ Drought Exposure Index.

We divided LGAs into quintiles based on the DRI value, and attributing LGAs with a Drought Risk Index scaled from 1 to 5 . 


\subsection{Design of a web-based GIS application for a DRA}

DRA, a web-based information App, displays a map of drought risk (level 1 product), maps of the drought hazard, vulnerability and exposure indices (level 2 products), and their indicators, e.g., the SPI, the VHI, SM, topographic layers, LGAs drought related population vulnerability indicators etc. (level 3 products).

The DRI map was produced by integrating the DHI, DVI and DEI maps using the fuzzy gamma overlay function in ArcGIS. The extent of drought hazard, vulnerability, exposure and risk displayed on the respective maps was classified into five categories based on the quintile values: mild (1), moderate (2), serious (3), severe (4), and extreme (5).

The designed web-based DRA App allows users to query the latest values of drought hazard indicators and indices updated monthly, as well as archived historical data. The DRA App will be also beneficial for researchers and LGA planners to gain insights on the current state of drought risk at both local and national levels.

In addition, statistics and plots, e.g., pie charts and boxplots, could be generated as level 4 products (as examples, an overview of DRI LGA distribution across states and territories is presented in Appendix 2 and a map of top 10 DRI LGAs - in Appendix 3).

\subsection{DRA App with an interactive dashboard and maps}

We built a DRA App in GIS to disseminate the DRI indicators and Index using an interactive dashboard and maps. Multiple layers representing indicators and indices were uploaded to the maps for visualisation, query and generating graphics.

To compute the DHI, users have a choice to select the SPI, the VHI and SM individually, or in combination, and then the selected indicators are used to compute the index. Similarly, a flexible approach is incorporated in computing the DVI, allowing users to select a set of indicators which is tailored to users' needs.

In this study, only land use/cover types from ALUM Class 3, Production from Dryland Agriculture and Plantations, were selected as inputs for the computation of the DEI. In the developed DRA design, there is an option for users to make a selection from a number of ALUM Class 3 types of land use/cover, e.g., grazing modified pastures, cropping, perennial horticulture, etc., could be selected individually or in combination to examine exposure to drought. In our future work, an option to add other ALUM Classes of land use/cover will be explored.

Assessing drought exposure, we used a non-compensatory method to combine selected indicators; this implies that superiority in one indicator cannot be offset by inferiority in another indicator. Thus, an LGA is highly exposed to drought if at least one of the indicators is abundant there. For example, an LGA that is completely covered by rain-fed crops is considered as fully exposed to drought, independently of the presence or absence of livestock.

Once the indicators for drought hazard, vulnerability and exposure are selected, they are combined with a built-in algorithm using equation 1 , and maps are generated.

\subsection{Case study for the 2019 drought in Australia}

Using a case study for the 2019 drought in Australia, we illustrate mapping functionality implemented in the designed web-based DRA App. In Figure 2, the DRI for Australia (level 1 product) for October 2019 is presented indicating severe (4) and extreme (5) drought risk for many LGAs in Australia.

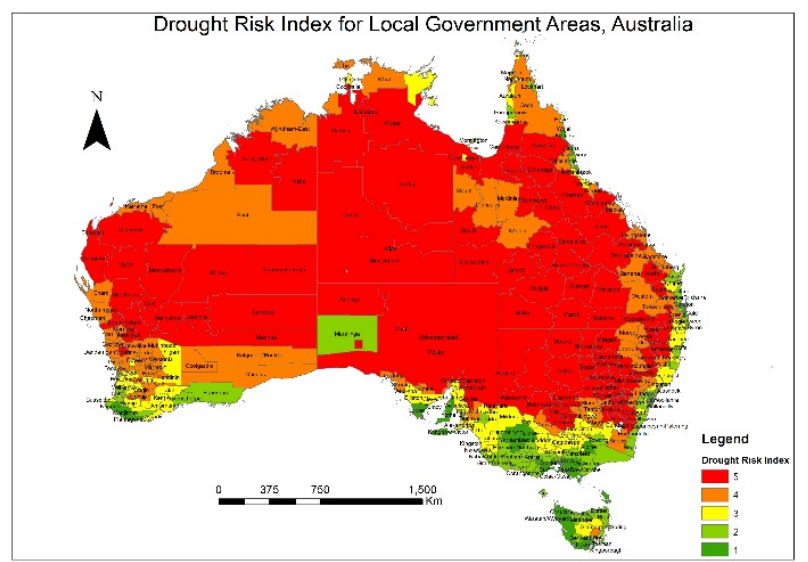

Figure 2. DRI at LGA level for Australia for October 2019

As an example of level 2 products, a map of the DHI index for Australia for October 2019 is presented in Figure 3. The index was computed using the SPI, the VHI and SM combined. The map indicates severe (4) and extreme (5) drought conditions for most of LGAs across the country apart from some LGAs in Victoria and Tasmania. Other examples of level 2 products maps of drought vulnerability and drought exposure - are given in Appendix 4 and Appendix 5 respectively.

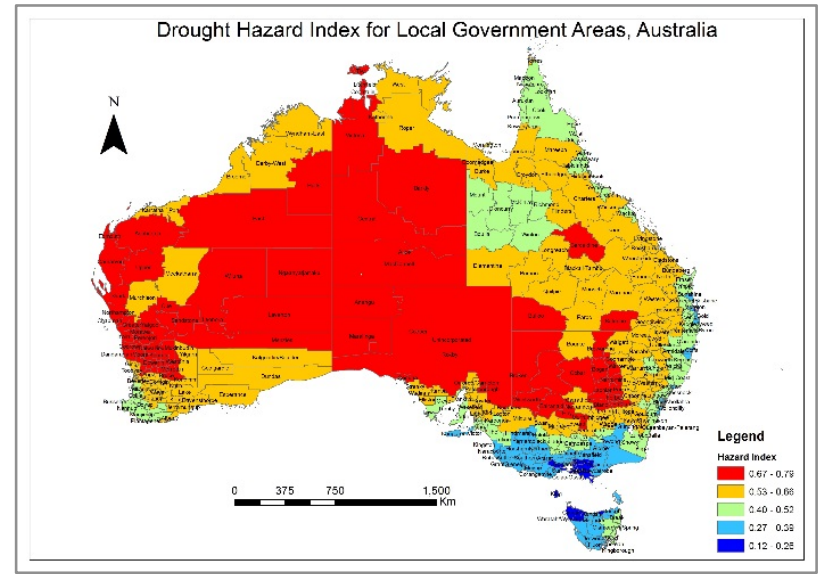

Figure 3. DHI for Australia for October 2019

Examples of level 3 products presented here include maps of three drought indicators used in calculating the DHI - the SPI, the VHI and SM. A map of the 90-day SPI for Australia for October 2019 is presented in Figure 4; a map of the VHI for October 2019 - in Figure 5, and a map of SM for October 2019 - in Figure 6. 


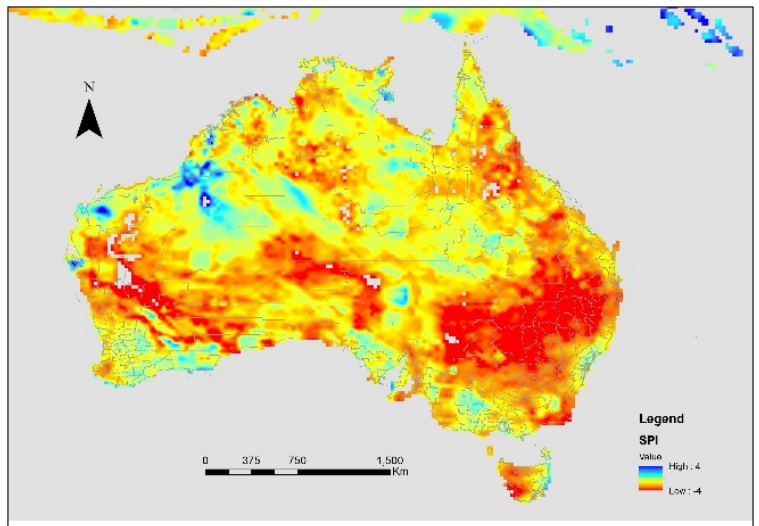

Figure 4. 90-day SPI for Australia ending 31 October 2019

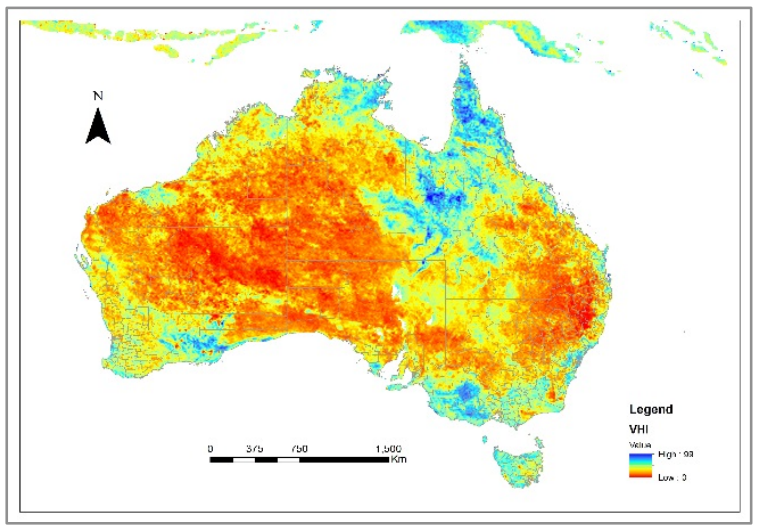

Figure 5. VHI for Australia for October 2019

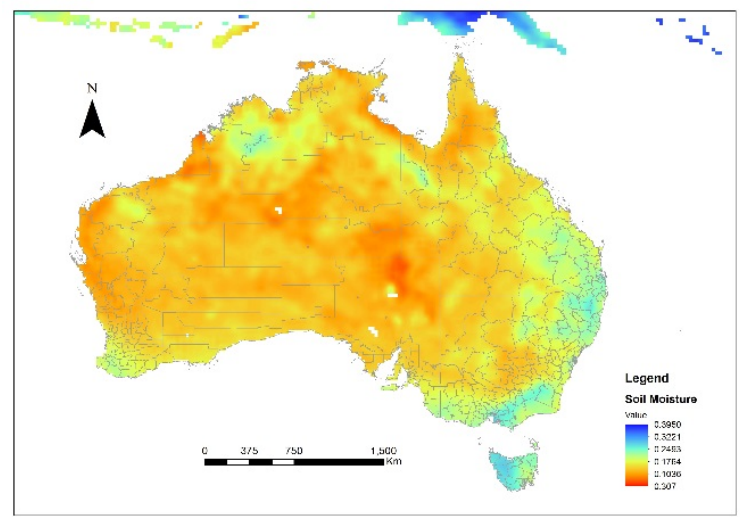

Figure 6. SM for Australia for October 2019

All the selected indicators clearly demonstrate severe rainfall deficiency and its impact on vegetation health and soil moisture content, collectively describing extremely dry conditions which many parts of Australia experienced in October 2019.

The DRA App also includes charts and gauges to show the statistics of the indicators (Figure 7). Dashboard elements were configured to communicate with each other. A set of widgets were built in to enable interaction with the map (e.g., layer visibility, search, sharing, etc.). Furthermore, a spatial analysis was included in the App, e.g., Figure 8 presents the local correlation between the SPI and the VHI.

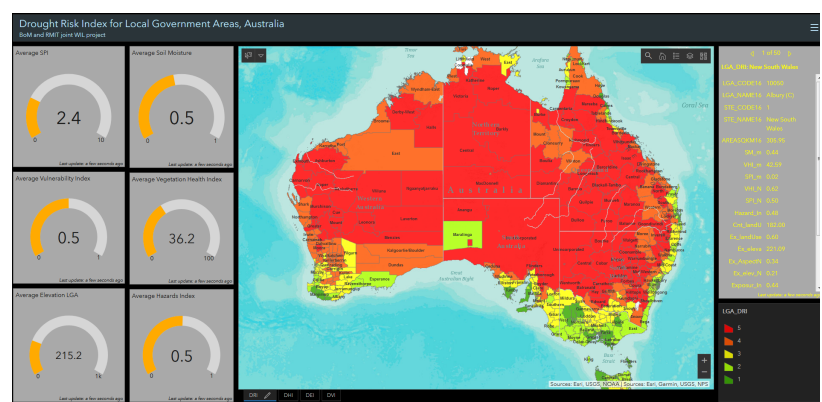

Figure 7. Web GIS Dashboard for DRA

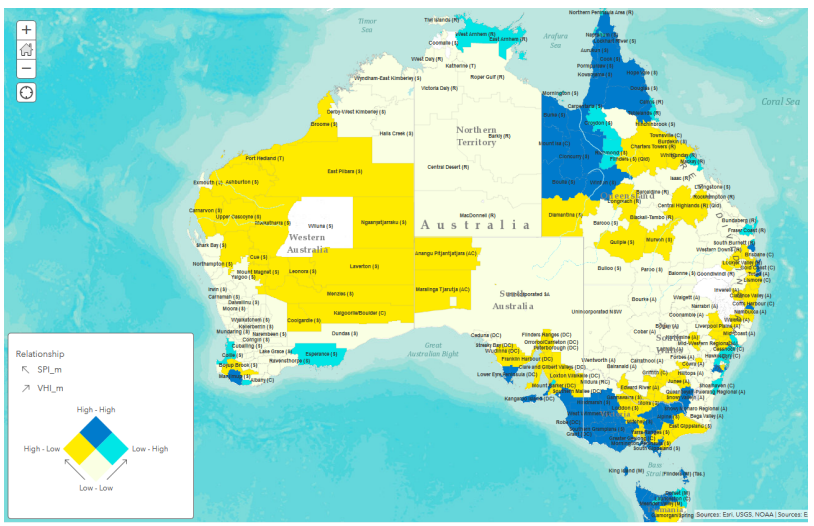

Figure 8. Local correlation map for the SPI and the VHI

In summary, this case study for the 2019 drought in Australia demonstrates that the developed DRA App is informative and interactive, whilst also having effective educational and decision-making functionalities.

\subsection{Further Development of a DRA}

In this paper, we presented a conceptual design of a Drought Risk Analyser, DRA, and illustrated its functionality using a case study of drought risk assessment for Australia in 2019.

As part of a peer-review process, useful comments on further improvement of the developed web-based App were received from GIS experts suggesting the implementation of additional functionality which will allow the derivation of statistics for spatial units defined under the Australian Statistical Geography Standard (ASGS). The ASGS is a hierarchical geographical classification, defined by the ABS, which is used in the collection and dissemination of official statistics. The possible implementation of these suggestions to enhance the functionality of the designed DRA App will be explored in our future work.

Further developing the DRA App, we will explore ASGS hierarchical structure. In order to provide spatially explicit DRI maps and robust statistical analysis, we will compute the level 3 products at the Statistical Area 1 (SA1) level. SA1s have a population of between 200 and 800 people with an average population size of approximately 400 people. The SA1 based drought risk indicators, three components of the drought risk index (DHI, DVI and DEI) and the final DRI can be aggregated into products at higher hierarchical levels, e.g., Statistical Area 3 (SA3) and LGA levels. SA3s are designed to provide a regional breakdown of Australia. They generally have a population of between 30,000 and 130,000 people. The ASGS LGAs are an ABS approximation of gazetted local government boundaries as defined by each State and Territory Local Government Department. As a result, the web-based Drought 
Risk Analyser will be a scalable and hierarchical decisionmaking tool for federal, state and local governments to query, compare and run statistics for a variety of decision support applications related to drought monitoring and strategic planning.

In this concept design of the DRA App, drought hazard assessment is based on using drought monitoring products - the SPI, the VHI and SM - from the WMO SWCEM; the products are available for East Asia and Western Pacific. While the presented case study describes the application of the DRA for drought risk assessment for LGAs in Australia, availability of space-based observations which provide global coverage will allow us to extend this approach and use the DRA App for assessment of drought risk in other countries. In the near future, spatial coverage for WMO SWCEM products will be extended beyond the Asia-Pacific region to include Africa and South America. As a result, more countries around the world affected by drought could potentially benefit from using the DRA App for improving drought preparedness of farming communities.

Severe, frequent and prolonged droughts have a detrimental impact on the productivity of agriculture sector; farming communities in developing and least developed countries in Africa, Asia-Pacific and South America are particularly vulnerable due to their low capacity to cope with drought. The importance of a user-centred Integrated Early Warning System for Drought to assist communities at risk is now widely recognised. Accurate and timely drought early warnings could potentially save many lives and reduce hardship for affected communities. Moreover, proactively responding to predicted dry conditions, humanitarian aid agencies could trigger a set of actions including Forecast-based Financing ( FbF) assistance which is specifically focused on providing aid to communities most vulnerable to drought hazard (Asghari et al. 2020). The DRA App is an integral part of a user-centred Integrated Early Warning System for Drought and its further development will be focused on addressing the needs of users in drought-prone areas around the world.

\section{CONCLUSIONS}

In this paper, we presented a conceptual design for a DRA web-based information App for drought risk mapping developed using GIS. The developed DRA is based on combining drought hazard, vulnerability and exposure to provide users with an integrated drought risk assessment. The presented case study for drought risk assessment in Australia in 2019 demonstrates flexible functionality of the DRA and its ability to generate various maps, graphs and statistics which could be brought down to a level of an individual LGA. Dashboards present the data in intuitive and compelling ways. The DRA App will be beneficial for Australian farmers and rural communities to assist with decision making, as well as for LGA planners to gain insights on current and future states of drought risk at both local and national levels.

\section{ACKNOWLEDGEMENTS}

Satellite-derived products used in this study for drought monitoring were provided through the World Meteorological Organization (WMO) Space-based Weather and Climate Extremes Monitoring (SWCEM) demonstration project for East Asia and Western Pacific. The authors express sincere gratitude to two anonymous reviewers for their valuable comments on the possible enhancement of DRA design.

\section{DISCLAIMER}

The views and opinions expressed in this publication are those of the authors and do not necessarily reflect those of the Australian Government. While reasonable efforts have been made to ensure that the contents of this publication are factually correct, the Commonwealth does not accept responsibility for the accuracy or completeness of the contents, and shall not be liable for any loss or damage that may be occasioned directly or indirectly through the use of, or reliance on, the contents of this publication.

\section{REFERENCES}

ALUM, 2016. The Australian Land Use and Management (ALUM) Classification system https://www.agriculture.gov.au/abares/aclump/land-use/alumclassification (August 2020).

Aitkenhead, I., Kuleshov, Y., Watkins, A.B., Bhardwaj, J., Asghari, A., 2020. Assessing Agricultural Drought Management Strategies in the Northern Murray-Darling Basin. Natural Hazards (under review).

Asghari, A., Kuleshov, Y., Watkins, A.B., Bhardwaj, J., Aitkenhead, I., 2020. Improving Drought Resilience in Northern Murray-Darling Basin Farming Communities: Is Forecast-based Financing Suitable? Natural Hazards (under review).

Atlas, R., Wolfson, N., Terry, J., 1993. The effect of SST and soil moisture anomalies on GLA model simulations of the 1988 US summer drought. Journal of Climate, 6(11), 2034-2048.

Bhardwaj, J., Kuleshov, Y., Watkins, A.B., Aitkenhead, I., Asghari, A., 2020. Building Capacity for a user-centred Integrated Early Warning System (I-EWS) for Drought in the Northern Murray-Darling Basin. Natural Hazards (under review).

Carrão, H., Naumann, G., Barbosa, P., 2016. Mapping global patterns of drought risk: An empirical framework based on subnational estimates of hazard, exposure and vulnerability. Global Environmental Change, 39, 108-124.

Commonwealth of Australia, Bureau of Meteorology (BoM), 2020, http://www.bom.gov.au/climate/drought/archive.shtml (October 2020).

Emrich, C. T., Cutter, S. L., 2011. Social vulnerability to climate-sensitive hazards in the southern United States. Weather, Climate, and Society, 3(3), 193-208.

Esri. 2018. ArcMap: Release 10.6. 1.

Geoscience Australia. 2010. 3 second SRTM Digital Elevation Model (DEM) v01. Bioregional Assessment Source Dataset, http://data.bioregionalassessments.gov.au/dataset/12e0 731d-96dd-49cc-aa21-ebfd65a3f67a (July 2020).

Karnieli, A., Bayasgalan, M., Bayarjargal, Y., Agam, N., Khudulmur, S., Tucker, C., 2006. Comments on the use of the vegetation health index over Mongolia. International Journal of Remote Sensing, 27(10), 2017-2024. 
Kuleshov, Y., Kurino, T., Kubota, T., Tashima, T., Xie, P., 2019: WMO Space-Based Weather and Climate Extremes Monitoring Demonstration Project: First Outcomes of Regional Cooperation on Drought and Heavy Precipitation Monitoring for Australia and Southeast Asia. In Rainfall - Extremes, Distribution and Properties, doi:10.5772/intechopen.85824

Livada, I., Assimakopoulos, V. 2007. Spatial and temporal analysis of drought in Greece using the Standardized Precipitation Index (SPI). Theoretical and Applied Climatology, 89(3-4), 143-153.

Svoboda, M., LeComte, D., Hayes, M., Heim, R., Gleason, K., Angel, J., Rippey, B., Tinker, R., Palecki, M., Stooksbury, D., Miskus, D. and Stephens, S., 2002. The Drought Monitor. Bulletin of the American Meteorological Society, 83(8):11811190.

Vogt, J.V., Naumann, G., Masante, D., Spinoni, J., Cammalleri, C., Erian, W., Pischke, F., Pulwarty, R., Barbosa, P., 2018. Drought Risk Assessment. A conceptual Framework. EUR $29464 E N$, Publications Office of the European Union, Luxembourg. ISBN 978-92-79-97469-4, doi:10.2760/057223, JRC113937.

\section{APPENDIX}

Appendix 1: Three levels of products for drought risk assessment.

Level 3

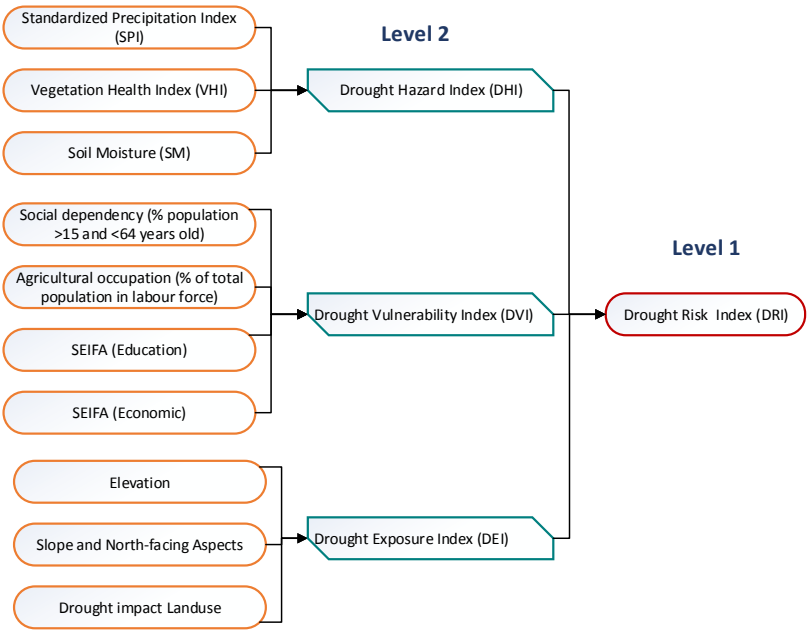

Appendix 2: Overview of DRI LGA distribution across states and territories.

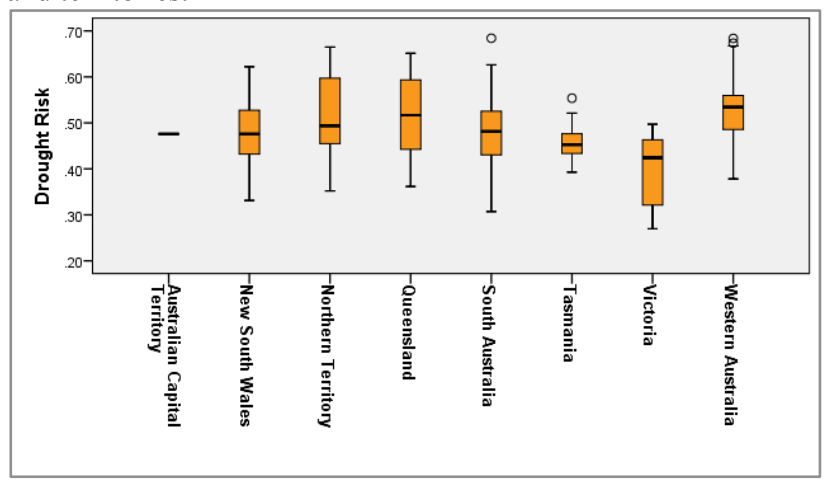

Appendix 3: Map of the top 10 DRI LGAs.

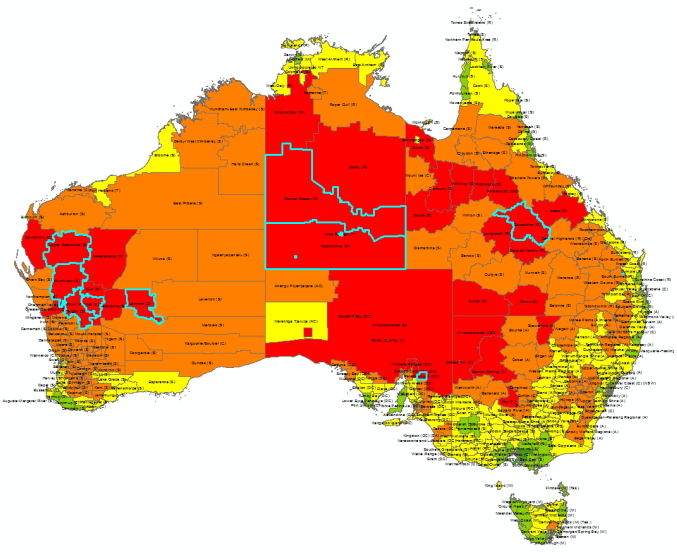

Appendix 4: Map of Drought Vulnerability Index for LGAs.

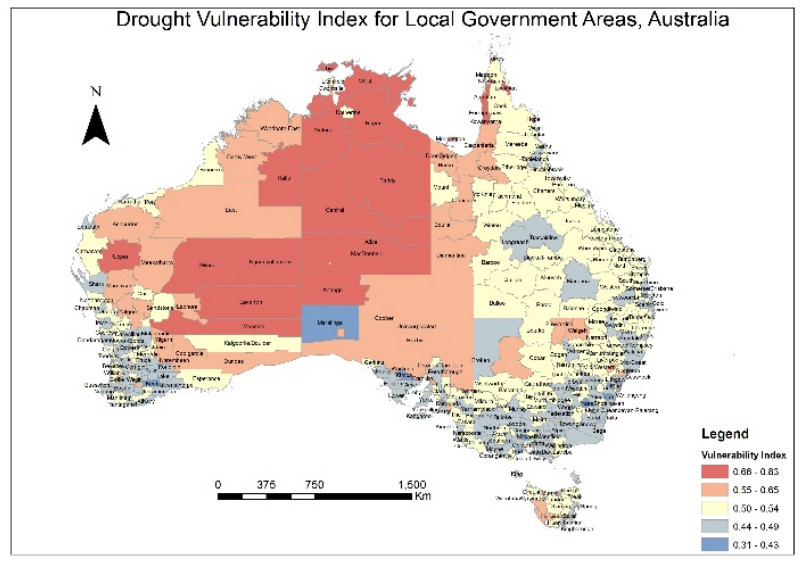

Appendix 5: Map of Drought Exposure Index for LGAs.

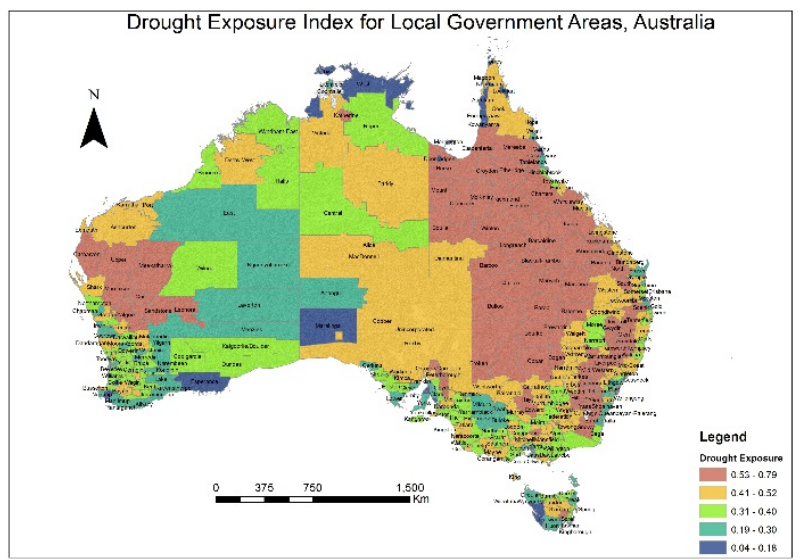

